\title{
Constructing of An Educational Program for Primary School Teachers Regarding Hepatitis A Control In Kirkuk Governorate
}

\author{
Naryman Mohammed Ahmed*
}

\author{
Dr. Rifaie Yaseen Hameed **
}

\begin{abstract}
Background and aims: In most cases of a single child with a common childhood communicable disease, the only action necessary is to ensure that the infectious child stays away from school whilst infectious and to be vigilant for further cases developing. The study objected to evaluate an educational program for primary school teachers about Hepatitis 'A' as one of the common childhood communicable disease in Kirkuk governorate .

Materials and method: A Quasi-experimental study was carried out through the present study with application of pre and post-tests approach. A probable (stratified) sample consist of (80) teachers who participated voluntarily from (80) primary schools in Kirkuk governorate They were divided into two equal groups of (40) teacher, one group was exposed to educational program (study group), while the second did not exposed to the program (control group). Data were analyzed using SPSS version-18.

Results: The results show that there are statistical significant differences in teachers' knowledge, attitudes and practices regarding all topics of Hepatitis A in comparison of pre and post tests for study group.

Conclusion: The study show that there is good acquisition in teachers' knowledge, attitudes and practices about Hepatitis A.
\end{abstract}

Keywords: Hepatitis " A", teachers, construct, knowledge, attitude.

\section{INTRODUCTION}

Hepatitis "A", one of the oldest diseases known to humankind, is a self-limited disease which results in fulminate hepatitis and death in only a small proportion of patients. However, it is a significant cause of morbidity and socioeconomic losses in many parts of the world (WHO, 2000). Geographic areas can be characterized by high, intermediate or low levels of endemicity patterns of Hepatitis viral infection. The levels of endemicity correlate with hygienic and sanitary conditions of each geographic area (WHO, 2010). In developing countries with very poor sanitary and hygienic conditions (parts of Africa, Asia and Central and South America), infection is usually acquired during early childhood as an asymptomatic or mild infection. Reported disease rates in these areas are therefore low and outbreaks of disease are rare, while in countries with transitional economies and some regions of industrialized countries where sanitary conditions are variable (Southern and Eastern Europe, some regions in the Middle East), children escape infection in early childhood. Paradoxically, these improved economic and sanitary conditions may lead to a higher disease incidence, as infections in older age groups, and reported rates of clinically evident hepatitis "A", but in developed countries (Northern and Western Europe, Japan, Australia, New Zealand, USA, Canada) with good sanitary and hygienic conditions, infection rates are generally low. In countries with very low hepatitis " $A$ " viral (HAV) infection rates, disease may occur among specific risk groups such as travelers (WHO, 2009).

Day care and school staff have a key role in preventing the transmission of diseases in day-care and school environment (Australian Department of Health, 2010). Any program provides advices for teachers can help to minimize the spread of infection in schools (Baxter, 2005).The risk of transmission of most communicable diseases can be reduced significantly by routine attention to basic hygiene. All staff and children should be encouraged to maintain control spread of communicable disease and straightforward basic good practices. Infections can be passed on before a person is knowingly unwell (Health protection agency, 2005). This study objected to construct an educational program in respect to Hepatitis "A" for primary teachers in Kirkuk governorate. 


\section{MATERIALS AND METHOD}

In order to achieve the objective of the present study a quasi-experimental design was depended for the period (1/7/2011 through 20/4/2012). A probable (stratified) sample of (80) teachers were participated voluntarily from (80) primary schools in Kirkuk governorate (who gave their approval). The method of sampling followed was by dividing the governorate to districts (inside and outside Kirkuk city), then selected in a probable manner one school from each district and one teacher from each school appointed. The sample was divided into two equal groups of (40) teacher, one group was exposed to educational program (study group), while the second did not exposed to the program (control group).

To construct the educational program, five steps were undertaken:

1. Depending on reviewing diseases profile of Health Directorate in Kirkuk, and consulting many professional physicians in the directorate, it was obvious that (Hepatitis A) had high prevalence rates among primary school pupils, so, the researchers selected the disease to construct an educational program regarding it and applicated it on the primary school teachers.

2. A special questionnaire was developed after reviewing many related literatures, it composed from two parts, part-1; Sociodemographic data as: age, gender, years of service, part-2; fourteen items about hepatitis " $A$ " (seven for knowledge, five for practice and two for attitudes), the questionnaire was exposed to twenty-one experts for validation, their comments were undertaken in the final draft of the tool, while the reliability of the tool was measured through a technique of test-retest after application on ten teachers out of the study sample, it was $(\mathrm{r} .=0.83)$.
3. Pre-test for the subjects was carried out to indicate their levels of knowledge, practice and attitude about the selected disease for study and control groups.

4. The educational program was constructed regarding the disease taking into consideration the subjects' knowledge, attitudes and practices in respect to the disease. It was applicated as three lectures for three days in-between on the study group in a special hole in one of the schools inside the city. The researchers used audio-visuals related as posters, videos in addition to discussions between the subjects and the researchers, each lecture took between (1 1.5) hour.

5. Post-test for the subjects in the study group was carried out to indicate the acquisition of knowledge, practice and attitude in respect to the disease after three weeks of carrying out the program.

All items had two options (correct=1) while (incorrect=zero). SPSS version-18 computer software was used for analysis of data. The statistical measures used were; mean and standard deviation as descriptive statistic, and ttest for paired samples as inferential statistic. The probability value depended to indicate the significance was (p. $\leq 0.05)$.

\section{RESULTS}

Table (1): Socio-demographic Characteristics of the Subjects in Study and Control Groups:

\begin{tabular}{|c|c|c|c|c|c|}
\hline \multicolumn{2}{|c|}{ Variables } & \multicolumn{2}{c|}{ Study group } & \multicolumn{2}{c|}{ Control group } \\
\cline { 3 - 6 } & & No.(40) & $\%$ & No.(40) & $\%$ \\
\hline \multirow{3}{*}{ Gender } & Female & 15 & 37.5 & 11 & 27.5 \\
\cline { 2 - 6 } Age & Male & 25 & 62.5 & 29 & 72.5 \\
\hline \multirow{3}{*}{ Years of work } & $25-34$ & 16 & 40 & 18 & 45 \\
\cline { 2 - 6 } & $35-44$ & 11 & 27.5 & 14 & 35 \\
\cline { 2 - 6 } & $45-54$ & 13 & 32.5 & 8 & 20 \\
\cline { 2 - 6 } & Less than 5years & 11 & 27.5 & 13 & 32.5 \\
\cline { 2 - 6 } & $5-9$ & 11 & 27.5 & 7 & 17.5 \\
\cline { 2 - 6 } & $10-14$ & 4 & 10 & 10 & 25 \\
\hline
\end{tabular}


Table (2): Comparison between Pre-test Scores for Study and Control Groups regarding Hepatitis "A" by using t-test.

\begin{tabular}{|c|c|c|c|c|c|c|c|}
\hline Topics & \multicolumn{2}{|c|}{ Per- test study group } & \multicolumn{2}{c|}{ Pre-test control group } & & & \\
\hline Hepatitis A & mean & SD & mean & SD & d.f. & T-test & Sig \\
\hline Knowledge & 3.77 & 0.97 & 3.62 & 1.33 & 39 & 0.53 & 0.59 \\
\hline Practice & 1.40 & 0.63 & 1.62 & 0.54 & 39 & 1.65 & 0.10 \\
\hline Attitudes & 1.40 & 0.87 & 1.67 & 0.91 & 39 & 1.35 & 0.18 \\
\hline
\end{tabular}

Table (3): Comparison between Post-test Scores for Study and Control Groups regarding Hepatitis "A" by using t-test.

\begin{tabular}{|c|c|c|c|c|c|c|c|}
\hline Topics & \multicolumn{2}{|c|}{ Post- test study group } & \multicolumn{2}{c|}{ Post-test control group } & & & \\
\hline Hepatitis A & mean & SD & mean & SD & d.f. & T-test & Sig \\
\hline Knowledge & 6.55 & 0.71 & 2.50 & 0.93 & 39 & 22.20 & 0.00 \\
\hline Practice & 1.72 & 0.45 & 0.87 & 0.40 & 39 & 8.11 & 0.00 \\
\hline Attitudes & 4.02 & 0.99 & 0.85 & 0.80 & 39 & 18.95 & 0.00 \\
\hline
\end{tabular}

Table (4): Association between Post-test of KAP scores in regard to Hepatitis "A" with Gender of the Study Group by using t-test.

\begin{tabular}{|c|c|c|c|c|c|c|c|}
\hline Topics & \multicolumn{2}{|c|}{ Female } & \multicolumn{2}{c|}{ Male } & & & \\
\hline Hepatitis A & mean & SD & mean & SD & d.f. & T-test & Sig \\
\hline knowledge & 6.66 & 0.81 & 6.48 & 0.65 & 39 & 0.79 & 0.43 \\
\hline practice & 1.80 & 0.41 & 1.68 & 0.47 & 39 & 0.80 & 0.42 \\
\hline attitudes & 4.00 & 0.92 & 4.04 & 1.05 & 39 & 0.12 & 0.90 \\
\hline
\end{tabular}

Table (5) Analysis of Variance of Teachers' Knowledge, Attitudes and Practices for Post-test scores regarding age of study group;

\begin{tabular}{|c|c|c|c|c|c|c|}
\hline $\begin{array}{c}\text { Topics } \\
\text { Hepatitis(A) }\end{array}$ & Groups & SS & d.f. & MS & $\mathbf{F}$ & Sig \\
\hline \multirow{3}{*}{ Knowledge } & Between groups & 0.52 & 2 & 0.26 & \multirow{3}{*}{0.504} & \multirow{3}{*}{0.608} \\
\hline & Within groups & 19.37 & 37 & 0.25 & & \\
\hline & Total & 19.9 & 39 & & & \\
\hline \multirow{3}{*}{ Practice } & Between groups & 0.82 & 2 & 0.41 & \multirow{3}{*}{0.398} & \multirow{3}{*}{0.675} \\
\hline & Within groups & 38.15 & 37 & 1.03 & & \\
\hline & Total & 38.97 & 39 & & & \\
\hline \multirow{3}{*}{ Attitudes } & Between groups & 0.12 & 2 & 0.06 & \multirow{3}{*}{0.287} & \multirow{3}{*}{0.752} \\
\hline & Within groups & 7.85 & 37 & 0.21 & & \\
\hline & Total & 7.97 & 39 & & & \\
\hline
\end{tabular}

Table (6) Analysis of Variance of Teachers' Knowledge, Attitudes and Practices for Post-test Scores regarding Years of Work for Study Group;

\begin{tabular}{|c|c|c|c|c|c|c|}
\hline $\begin{array}{c}\text { Topics } \\
\text { Hepatitis(A) }\end{array}$ & Groups & SS & d.f. & MS & $\mathbf{F}$ & Sig \\
\hline \multirow{3}{*}{ Knowledge } & Between groups & 2.56 & 6 & 0.42 & \multirow{3}{*}{0.813} & \multirow{3}{*}{0.568} \\
\hline & Within groups & 17.33 & 33 & 0.52 & & \\
\hline & Total & 19.90 & 39 & & & \\
\hline \multirow{3}{*}{ Practice } & Between groups & 6.28 & 6 & 1.13 & \multirow{3}{*}{1.167} & \multirow{3}{*}{0.347} \\
\hline & Within groups & 17.33 & 33 & 0.97 & & \\
\hline & Total & 19.90 & 39 & & & \\
\hline \multirow{3}{*}{ Attitudes } & Between groups & 0.61 & 6 & 0.1 & \multirow{3}{*}{1.357} & \multirow{3}{*}{0.261} \\
\hline & Within groups & 7.36 & 33 & 0.22 & & \\
\hline & Total & 7.97 & 39 & & & \\
\hline
\end{tabular}




\section{DISCUSSION}

Children, especially those at school age are at increased risk of infectious diseases due to their increased activity, poor knowledge and inappropriate personal health practices. Nurses role as counseling or adviser impede on them the responsibility of health teaching to prevent these diseases. To achieve that, constructing an educational program about infectious disease is necessary to help teachers developing their knowledge, practices and attitudes to insure safety of children. The important limitation the researches faced was that there is no any related literature about such health program regarding the communicable diseases among teachers.

In this study, the researchers assessed knowledge, attitudes and practices in respect to Hepatitis "A" as one of the common childhood communicable diseases as a trial to determine the weakness points they had in respect to the disease, also to construct and implement such educational program regarding that. Throughout the course of data analysis, it depicted that more than two thirds of the study sample were males $(62.5,72.5 \%)$ in study and control groups respectively (table-1). This result is in agreement with a study done by Mushtaq and colleagues (2011). Relative to age, the age group of (25-34) years of the study and control groups accounted highest proportions $(40 \%, 45 \%)$ respectively (Table- 1). This result is in agreement with the findings of a previous study done by Girgis and colleagues (2011). Regarding years of employment, more than one quarter of the study group had less than five years of employment in addition to the same percentage of the category of (5-9) years, also, 1/3 of control group were from the category of less than five years of employment as $(27.5 \%, 32 \%)$ respectively (Table- 1).

Prior to implementation of the educational program, a pre-test was carried out on both groups (study and control). It was found that there were no significant differences between the two groups at all topics related to the disease. It means that teachers had the same knowledge, attitudes and practices about the disease (Table2). After completion of the educational program, a comparison of post-test scores- that was administered for both groups three weeks laterwas carried out. Results indicated that there were significant differences among all topics related to the disease (Table- 3). This means that teachers had got improvement in their knowledge, attitudes and practices regarding the disease. This was agreed with findings of a pervious study (Wu, 2007). Results of teachers' KAP scores in respect to the demographic characteristics did not show any significant differences in all topics regarding to the disease (Tables- 4,5,6). These results can be due to many factors; smallness of the sample, importance of the program topics to the community that imposes liability on teachers to pay more attention to prevent any health problem related, the simplicity of the presentation of the information accompanies with the actuality of the explanation of the disease, commitment in attendance all sessions for the suitability of the time of sessions and number of it, stay far from routine style in presenting information and dependence on discussion and feedback for each information, in addition to use different audiovisuals, and the strong desire of teachers to enroll and attend all sessions of the program.

Children, especially those at school age are at increased risk of infectious diseases due to their increased activity, poor knowledge and inappropriate personal health practices. Nurses role as counseling or adviser impede on them the responsibility of health teaching to prevent these diseases. To achieve that, constructing an educational program about infectious disease is necessary to help teachers developing their knowledge, practices and attitudes to insure safety of children. The important limitation the researches faced was that there is no any related literature about such health program regarding the communicable diseases among teachers.

In this study, the researchers assessed knowledge, attitudes and practices in respect to Hepatitis "A" as one of the common childhood communicable diseases as a trial to determine the weakness points they had in respect to the disease, also to construct and implement such educational program regarding that. Throughout the course of data analysis, it depicted that more than two thirds of the study sample were males $(62.5,72.5 \%)$ in study and control groups respectively (table-1). This result is in agreement with a study done by Mushtaq and colleagues (2011). Relative to age, the age group of (25-34) years of the study and control groups accounted highest proportions $(40 \%, 45 \%)$ respectively (Table- 1). This result is in agreement with the findings of a previous study done by Girgis and colleagues (2011). Regarding years of employment, more than one quarter of the study group had less than five years of employment in addition to the same percentage of the category of (5-9) years, also, 1/3 of control group were from the category of less than five years of 
employment as $(27.5 \%, 32 \%)$ respectively (Table- 1).

Prior to implementation of the educational program, a pre-test was carried out on both groups (study and control). It was found that there were no significant differences between the two groups at all topics related to the disease. It means that teachers had the same knowledge, attitudes and practices about the disease (Table2). After completion of the educational program, a comparison of post-test scores- that was administered for both groups three weeks laterwas carried out. Results indicated that there were significant differences among all topics related to the disease (Table- 3). This means that teachers had got improvement in their knowledge, attitudes and practices regarding the disease. This was agreed with findings of a pervious study (Wu, 2007). Results of teachers' KAP scores in respect to the demographic characteristics did not show any significant differences in all topics regarding to the disease (Tables- 4,5,6). These results can be due to many factors; smallness of the sample, importance of the program topics to the community that imposes liability on teachers to pay more attention to prevent any health problem related, the simplicity of the presentation of the information accompanies with the actuality of the explanation of the disease, commitment in attendance all sessions for the suitability of the time of sessions and number of it, stay far from routine style in presenting information and dependence on discussion and feedback for each information, in addition to use different audiovisuals, and the strong desire of teachers to enroll and attend all sessions of the program.

\section{CONCLUSIONS}

The study concludes that there is a lack of teachers' knowledge, attitudes and practices in regard to the disease before implementation the educational program. Good acquisition of knowledge, attitudes and practices after implementation of the educational program. In addition, Demographic characteristics of teachers had not indicated obvious association with knowledge, attitudes and practices regarding the disease after implementation the educational program.

\section{RECOMMENDATIONS}

Construct of an Infectious Disease Control Guidelines for schools by Ministry of Health about childhood communicable disease to help teachers to prevent and control such disease among pupils. In addition, the present study recommends that applying such educational health programs in all Iraqi governorate primary schools to increase awareness about communicable diseases control among teachers. Inclusiveness other communicable diseases in such educational health programs.

\section{REFERENCES}

Australian Department of Health, Government of Western Australia. (2010). Communicable Disease Guidelines for teachers, childcare workers, local government authorities and medical practitioners. Prevention and control program, Department of Health. Australia. p 2.

Baxter, D. (2005). Infection control and cross infection guidelines for school, control of infection unite. (6 ${ }^{\text {th }}$ ed.)Stockport NHS. p13.

Girgis, N., Elbahnasawy, H., and Omer, T. (2011). Changing Mothers' Behavior to prevent Viral Infctious Diseases among their Children by using Health Belief Model. Canadian Journal of Medicine.2(2)p29-33.

Health protection agency. (2005). The control of communicable diseases in schools and nurseries. $\mathrm{p} 5$.

Mushtaq, M., Shahid, U., Abdullah, H., Saeed, A., Omer, F., Siddiqui, A. (2011). UrbanRural Inequities in Knowledge, Attitude and practices regarding tuberculosis in two Districts of pakistan's Punjab province. International journal for Equity in Health. $10(8) . \mathrm{p} 2-6$.

World Health Organization (WHO). (2000). Hepatitis A - An Introduction, Hepatitis A, Department of Communicable Disease Surveillance and Response. $\mathrm{p} 4$.

World Health Organization a (WHO). (2010). Postgraduate Programs School of Public Health and Community Medicine, Communicable Diseases Humanitarian Emergencies. p 3.

World Health Organization d (WHO). (2009). Hepatitis A Virus, The Global Prevalence of Hepatitis A Virus Infection and Susceptibility: A Systematic Review, Department of Immunization, Vaccines and Biologicals (IVB). Switzerland,WHO.p4-6.

$\mathrm{Wu}$, C. (2007). Effectiveness of a Specific Infection Control Education Program for Taiwanese Nursing Students, Queensland University of Technology. Institute of Health and Biomedical Innovation, School of Nursing. p 115-138. 